\title{
The competitiveness of small and medium enterprises in the tourism sector: the role of leadership competencies
}

\author{
Le Chi Cong and Dao Anh Thu \\ Faculty of Tourism, Nha Trang University, Nha Trang, Vietnam
}

Competitiveness

of SMEs in

tourism

\begin{abstract}
Purpose - This research aims to adopt competitiveness theory to analyse the effects of leadership competencies on the competitiveness of small and medium-sized enterprises (SMEs) in the tourism sector. Design/methodology/approach - This research collected data from 200 participants, who are in management positions of tourism SMEs in Vietnam. Structural equation modelling was applied.

Findings - The results indicate satisfactory reliability and validity of the constructs and support for two models within a structural equation modelling to evaluate the influence of leadership competencies on the competitiveness of SMEs. The data from both customers and competitors show that the competitiveness and the performance of the enterprise are affected by hands-on experience; relationships building competencies; strategic vision; operations management competencies. Furthermore, customers also value professional knowledge of the enterprises' leaders.

Practical implications - The study suggests that the government agencies and tourism SMEs themselves should focus more on leadership. Training courses, exchange programs, seminars and workshops should be provided for SMEs leaders to improve their leadership competencies.

Originality/value - The research findings provide a more comprehensive view of internal and external factors affecting the competitiveness of SMEs in the tourism sector in Vietnam. This also contributes to competitiveness and leadership research by presenting the positive linkage between leadership competencies and the competitiveness of SMEs.
\end{abstract}

Keywords SMEs, Leadership competencies, Tourism, Vietnam

Paper type Research paper

\section{Introduction}

Research on the competitiveness of enterprises is not a new topic in Vietnam academic field (Tho and Trang, 2009). Many studies have conducted from the perspective of Porter's theory of competitiveness and competitive advantage (1985) to develop conceptual and empirical studies (Kamp and Parry, 2017; Man et al., 2002). The concept of competitiveness has been continued to develop in three levels, which are enterprise, industry and country; and it has attracted the attention of many business researchers (Bharadwaj et al., 1993; Goldberg et al., 2003). In Vietnam, several researchers in different fields have applied the theory of competitiveness and competitive advantage to explore the factors that contribute to the competitiveness of businesses (Tho and Trang, 2009; An and Thi, 2012; Ai, 2013; Hieu et al., 2020). However, there has been no significant research on how leadership affects the competitiveness of small and medium enterprises in practice. Therefore, researchers continue carrying out several types of

(C) Le Chi Cong and Dao Anh Thu. Published in Journal of Economics and Development. Published by Emerald Publishing Limited. This article is published under the Creative Commons Attribution (CC BY 4.0) licence. Anyone may reproduce, distribute, translate and create derivative works of this article (for both commercial and non-commercial purposes), subject to full attribution to the original publication and authors. The full terms of this licence may be seen at http://creativecommons.org/licences/by/4.0/ legalcode

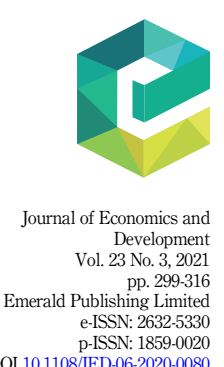

DOI 10.1108/JED-06-2020-0080 
JED

23,3

300

research in the Vietnamese context to form a comprehensive view of leadership factors affecting the competitiveness of small and medium enterprises (Cong and Hai, 2015).

Leaders play a vital role in shaping business goals, strategies and decisions (Asree et al., 2010). It has been recognised that leadership competencies are decisive factors for business success (Asree et al., 2010; Clarke, 2010). The leadership process means creating social influence to foster the voluntary participation of subordinates in implementing the vision, goals and mission of the organisation (Asree et al., 2010; Clarke, 2010). Leadership is the combination of knowledge, skills, experience, behaviours and attitudes to turn organisations or enterprises into a cohesive body to ensure successful competition in the marketplace (Church, 1995; Asree et al., 2010).

Regarding small and medium-sized enterprises (SMEs), leaders/managers have an important role in improving competitiveness, creating jobs, increasing incomes for employees and mobilising social resources for business development investment (Clarke, 2010; Cannon et al., 2010). However, most leaders/managers of SMEs, even those who have received higher education, lack in-depth knowledge of economics, business administration, business law and other key areas. This limitation has been found to have a significant impact on the enterprises' vision, goals, strategies and capability to cope with risks (Chawla et al., 1997). Notably, due to their small scale, SMEs are particularly vulnerable to an adverse business environment (Chawla et al., 1997).

Indeed, in Khanh Hoa during the past few years, there have been an increasing number of SMEs, which have been dissolved, are in hiatus, or went bankrupt. Arguably, one of the key causal factors is the weak management of human resources, especially the development of leadership competencies of the management team and the managers. The lack of adequate consideration of this aspect causes the difficulties for SMEs to develop (Cong and Hai, 2015). As the chief executor of an enterprise, the SME manager has to exercise leadership activities which are comprehensive and practical. Furthermore, he/she has to execute directly the production process and business operations, as well as perform leadership activities in human resources management.

To perform his/her role effectively, an SME manager needs strong leadership competencies, sufficient knowledge and skill set, attitudes and qualities to effectively lead not only himself/herself but also the team and the whole organisation. This serves the ultimate purpose, which is to maintain and develop the position of the enterprise in the market and generate legitimate income for the stakeholders and the manager himself/herself. This study aims to apply competitiveness theories to analyse leadership competencies affecting the competitiveness of SMEs. The results have practical implications to systematise theoretical issues, investigate the situation, identify the competencies that constitute the leadership of enterprises. Furthermore, the study offers recommendations on policy to improve the competitiveness of SMEs in the future.

\section{Literature review}

\subsection{Competitiveness}

Over the past 30 years, competitiveness has always been an attracting topic among scholars, businesses and government agencies. There are four levels of competitiveness, including product, firm, industry and nation (Porter, 2008). Today, competitiveness is also considered in terms of region and locality (Porter, 2008). Regarding the product, Goldberg et al. (2003) argued that the concept of competitiveness is related to the aspects of competitive advantage or price competitiveness, strategic management and historical, cultural - social aspects. Man et al. (2002) also approached corporate competitiveness from the perspective of price, service quality, gross profit and the ability to plan and achieve business goals compared to industry competitors. For the industry, competitiveness is understood as the ability to maintain or 
increase market share by low cost or product characteristics compared to a similar industry in different countries (Porter, 2008). Finally, national competitiveness is the competitiveness of a national economy to achieve and maintain high growth based on sustainable policies and institutions (WEF, 2003). This research studies the enterprise competitiveness and is mainly developed based on Porter's theory of competitiveness and competitive advantage $(1985,2008)$.

Competitiveness of SMEs in tourism

\subsection{Small and medium enterprises (SMEs)}

According to McAdam et al. (2004), there is no universal definition of SMEs, and this poses a challenge for studying SMEs. Commonly, the definitions of SMEs fall into two criteria. A quantitative criterion includes size, capital, annual turnover, invested capital, revenue, total assets, market share and so on (Hossain and Kauranen, 2016). Amongst these, the number of employees is the most common since it is available, easy to control and not affected by inflation (Filion, 1990; cited in Buculescu, 2013). However, Gibson and Van Der Vaart (2008) argued that it can be misleading because when an organisation develops or becomes more efficient, it does not always entail the recruiting of more people, thus affecting the growth of SMEs. Other qualitative categories such as turnover and balance sheet are also criticized as being suitable explanatory factors because they do not consider the type of the economic sector, and other business aspects (Buculescu, 2013). Furthermore, each country has its definition. For example, in Vietnam, according to the Government's Decree No. 39/2018/ ND-CP on March 11th, 2018, SMEs are business establishments that are legally registered. They are divided into three levels: micro, small, medium scale according to the total capital (total capital equal to the total assets determined in the enterprise's balance sheet) or the average number of employees per year, which is less than 200. The total capital is the primary criterion. By comparison, European SMEs are classified by the number of employees (under 250 people), and turnover or balance sheet (European Commission, 2003). The number of employees in SMEs in the USA, however, can be a maximum of 500 employees regarding business sector (the United States International Trade Commission, 2010), which is double the standard size of European SMEs and much larger than Vietnamese one.

A qualitative criterion considers the independent ownership of SMEs as the primary category, and it can be combined with qualitative criterion. For example, Recklies (2001, cited in Buculescu, 2013) defined an SME as a small entity, which is independent in terms of capital and does not possess a majority of market share. Other categories are the specification of the business sector, which is represented in the definitions of SMEs in the USA and China (Hossain and Kauranen, 2016); or management hierarchy, low specialised degree of executives (Mohamed et al., 2013). The qualitative criteria also focus on the disadvantages of SMEs such as lack of strong negotiating position (Mohamed et al., 2013); lack of sufficient financial resources (Abosede et al., 2016) as the owner has all responsibility for funding (Buculescu, 2013). As can be seen, the criteria of SMEs do not consider the business relationships, technology competencies, management competencies and performance.

\subsection{Competitiveness of small and medium enterprises}

The concept of competitiveness of different levels (enterprise, industry, country), has attracted the attention of both researchers and business managers (Bharadwaj et al., 1993; Goldberg et al., 2003). The concept of competitiveness relates to aspects such as competitive advantage, price competition, strategic management and other historical and socio-cultural aspects (Goldberg et al., 2003). Competitiveness can also be seen as an independent variable, intermediate variable or entirely dependent variable, depending on the perspective of the approach in the studies (Asree et al., 2010). In the hospitality sector, the competitiveness of 
JED

23,3

302

small and medium-scale hotels can be seen through the competitiveness of price, service quality, gross profit, planning and achieve business goals compared to their competitors (Fraj et al., 2015).

The competitiveness of enterprises is seen as the degree of interaction between the groups of customers' satisfaction and the value of shareholders by constantly improving service quality, the capability to exploit the potentials, to implement or to respond through financial strength (Asree et al., 2010). Business practices indicate that a SME is not a scaled-down version of a large enterprise (Chawla et al., 1997). SMEs differ in organisational structure, capital capacity, labour, technology, the capability to respond to the environment, management style and, more importantly, the fashion in which they compete with other enterprises (Chawla et al., 1997). Therefore, competitiveness studies focussing only on large corporations may not be applied directly to SMEs (Man et al., 2002; Chawla et al., 1997). Research, having studied the factors influencing the competitiveness of SMEs, has increased significantly in recent years (Asree et al., 2010).

Robinson (2005) emphasised that the assessment of the SMEs competitiveness should be considered in the wider interaction or placing it in the constant turbulence of the business environment and considering the capability to access capital sources and the internal capabilities of SMEs. Noticeably, to achieve a competitive advantage, internal resources play a more vital role than external factors (Zainudin et al., 2018). Although the hospitality sector has particular characteristics such as being influenced by seasonality, most of the enterprises are household businesses, meaning they are highly independent. These companies are equipped in advance; thus, they are not constrained by suppliers. Therefore, the competitiveness of small and medium-sized hotels is heavily influenced by the management competencies of business owners (Fraj et al., 2015; Cong and Hai, 2015). This approach addresses the consideration of the various environmental influences and impacts on the competitiveness of small and medium-sized hotels, with particular emphasis on the internal factors of the enterprise (Asree et al., 2010).

\subsection{Leaders}

The concept of "leaders" is often misunderstood and confused with many other concepts, especially with "managers", or "business owners". Misperceptions and inadequate understanding of the leaders themselves have affected the performance of many organisations or groups. Therefore, an understanding of the concept of "leader" is vital. Overall, a leader must ensure three capabilities: shaping a vision, inspiring and influencing (Anand and Punia, 2013). Stated differently, a leader is a person who is capable of creating a vision for an organisation or group and exercises his/her power to influence who follow that vision. More importantly, in the everchanging and turbulent business context, a leader also needs to develop trusting relationships with his/her subordinates and empower them by acknowledging and clarify their roles in the organisation (Martínez-Córcoles et al., 2020). Depending on a particular research aspect, researchers have different definitions of leaders.

\subsection{The influence of leadership competencies on the competitiveness of small and medium enterprises}

The leaders of the enterprises can manage and lead the organizations effectively only if they truly acquire knowledge of their business fields. In addition to requiring fundamental knowledge, leaders always need to be eager to learn to improve their awareness, knowledge and update new information (Anand and Punia, 2013) to develop their competencies in managerial and entrepreneurial aspects (Lenka and Agarwal, 2017; Man et al., 2002). Leaders play an important role in the establishment, survival and 
sustainable development of the organisations (Anand and Punia, 2013; Man et al., 2002). In particular, their role is even more important for SMEs because of their origins, size, characteristics and the nature of their business operations. SME leaders oversee almost all aspects of business operations. They are often referred to as general managers (GM) rather than Sspecialist managers (SM). Many studies have shown that the nature of general management, which involves almost all the activities, limits their strategic vision. The long-term ideas are outweighed by short-term tasks (Anand and Punia, 2013; Man et al., 2002). However, understanding and measuring the different influences of leaders on the competitiveness of SMEs is the subject of much debate. Several empirical studies show the strong influence of the factors belonged to leaders themselves on the competitiveness of enterprises (OECD, 1993; Goldberg et al., 2003; Anand and Punia, 2013; Man et al., 2002).

Some scholars emphasise that the professional knowledge of leaders relates to several aspects such as business development; awareness of the market and competitors, knowledge of marketing, knowledge of globalisation and integration. This competency also includes knowledge of society, community and environment to the effectiveness in developing and implementing the overall strategy. The results show that they affect the competitiveness of SMEs (Anand and Punia, 2013; Man et al., 2002; Chawla et al., 1997; Cong and Hai, 2015). In light of the arguments and analysis above, the context of SMEs in the tourism sector of Nha Trang, the hypothesis H1, H2 is proposed as follows:

H1,2. There is a positive relationship between the professional knowledge of leaders and the competitiveness of SMEs.

As a leader of a business, he/she needs to have a broad view and the capability to manage and lead all units of the business in a systematic, orderly and comprehensive manner. This competence will allow leaders to capture the overall business situations of the enterprise from planning, organising, directing to monitoring, evaluating and adjusting; from finance, human resources, marketing activities to production and services. Despite the differences in the research context, the research results of Goldberg et al. (2003) and Robinson (2005) in the context of developed markets as well as Cong and Hai (2015) in the context of the Vietnam market, emphasised the aspects of management competencies of leaders such as the capability to build organisational structure; managing business units; executive competencies; leadership and direction; decision-making competencies; implementing and evaluating, etc. These are considered as core competencies of leaders and thus relate to the competitive advantage of small and medium enterprises. Therefore, the hypothesis H3, H4 is presented as follows:

H3,4. There is a positive relationship between operations management competencies of leaders and competitive advantage of SMEs.

The vision of a leader demonstrates the capability to recognise and anticipate the changes taking place in the future business environment. If the leader has a clear vision, he/she can develop feasible strategies, implement the right plans and bring long-term profits to the business. Leaders must combine subjective awareness and the external factors to have a comprehensive view of threats that the enterprises are about to encounter (Anand and Punia, 2013; Man et al., 2002). Additionally, good strategic vision allows leaders to be adaptive in different circumstances, situations and environments. The ability to adapt, be sensitive and flexible also allows leaders to capture the rapid changes of the business environment, predict the trends of the market and incorporate these into suitable product development (Man et al., 2002). Recently, the research of Cong and Hai (2015), developed based on the research of Anand and Punia (2013), has added the factor of the importance of strategic vision for business leaders. This study argued that strategic vision is a component that directly affects 
JED

23,3

304

the competitiveness of SMEs. Specifically, the components of a business leader's strategic vision include the capability to identify business opportunities; the capability to seize opportunities to lead the enterprise to success; the capability to recognise and avoid risks and; the capability to see the business potential to develop. This study was conducted on SMEs in the tourism sector and showed that the strategic vision of leaders in SMEs affects the competitiveness of businesses. Therefore, hypothesis H5, H6 is proposed as follows:

H5,6. There is a positive relationship between the strategic vision of leaders and the competitiveness of SMEs.

In the current trend of international integration, establishing and building relationships in business is one of the key effective business strategies and an essential factor for business survival. A successful enterprise and a successful leader must always have a strategic vision in building and developing relationships and the capability to communicate effectively in seeking, developing and maintaining future relationships. For business leaders, relationship building is also considered one of the important criteria. It includes the capability to establish good relationships not only with strategic partners, customers and suppliers but also within the organisation. The support of firm managers to diversified, inclusive human resources management has a positive association with business performance (Kundu et al., 2019). Moreover, to retain profitable customers and gain competitive advantage, leaders need to cultivate the innovation culture, which encourages and fosters the creative thinking of employees (Hanifah et al., 2019). In particular, building relationships with local administrative agencies is also one of the considerable factors. Extending from the relationship quality perspective, the research of Tho and Trang (2009) found that the direct external effects of the relationship quality of enterprises on business results. Based on recent research by Anand and Punia (2013), Man et al. (2002), Chawla et al. (1997), Cong and Hai (2015), hypothesis H7, H8 is stated as follows:

H7,8. There is a positive relationship between relationships building competencies of leaders and competitive advantage of SMEs.

Anand and Punia (2013) stated that experience, knowledge and management skills are particularly important competencies of leaders to increase the competitiveness of SMEs. Chawla et al. (1997) argued that the experience and strategic orientation are two crucial factors of leaders that positively influence the competitiveness of SMEs. On the other hand, some studies refer to factors that belong to their characteristics such as age, gender, educational background or psychological and behavioural characteristics as well as their management skills, all of which have a profound impact on the competitiveness of SMEs.

Nevertheless, while some studies note that experience and knowledge acquired over time both have a positive effect on competitiveness and performance of SMEs, the age factor remains unclear and controversial (Goldberg et al., 2003; Robinson, 2005). For example, Goldberg et al. (2003) suggested that the older entrepreneurs are, the better their capability to make decisions is. However, Voola et al. (2012) stated the opposite. Therefore, the contrast in previous research results requires empirical studies to identify intrinsic factors of leaders influencing the competitiveness of SMEs. Thus, hypothesis H9, H10 is proposed as follows:

H9,10. There is a positive relationship between the hands-on experience of leaders and the competitiveness of SMEs.

Based on both domestic and foreign studies, as well as on the fundamental theories, the research model used here is developed to analyse how different characteristics of leaders affect the competitiveness of SMEs in the tourism sector. The dependent variables are built based on the measurement of the enterprise competitiveness in 
two aspects: (1) competitiveness and performance of enterprises compared to competitors and (2) competitiveness and performance of the enterprise from the perspective of customers.

\section{Methodology}

3.1 Data collection and analysis

3.1.1 Data description. Currently, Khanh Hoa has over 1,600 enterprises in the tourism sector. To be specific, the number of accommodation establishments accounts for a large proportion of 710. Among them, 250 companies are operating in travel service; 580 establishments in restaurants/food and beverage services and nearly 30 units in shopping and entertainment service. Of these, the proportion of SMEs is around $92 \%$. To gather a specific view regarding the influence of leadership competencies on the competitiveness of SMEs in Khanh Hoa tourism sector, a survey was conducted with 250 leaders/managers of SMEs in the province. There were 215 questionnaires collected. The number of questionnaires, which were incomplete and invalid, was 15 . Amongst 200 participants, there were 117 males and 83 females, accounting for 58.5 and $41.5 \%$, respectively. The number of participants with undergraduate and post-graduate degree occupied the largest proportion $(70.5 \%)$. The group having a college degree ranked second $(26.0 \%)$, and participants having attended junior college only constituted $3.0 \%$. The number of people with other educational backgrounds was the lowest at $0.5 \%$. The majority of participants were between 35 and 45 years old $(55.0 \%)$. The age group from 46 to 55 made up $26.0 \%$ with 52 participants. The group under 35 years old ranked third with 34 participants $(17.0 \%)$. The smallest proportion $(2.0 \%)$ was the group over 55 years old with four participants. The characteristics of the sample reflect the nature of the tourism sector, in which the workforce aged from 35 to 45 not only reaches maturity but also has youth and enthusiasm. The number of participants holding a division manager position was 130 , accounting for $65.0 \%$. There were 37 participants in the head/ deputy of department position (18.5\%) and 33 participants in other positions (16.5\%). 109 participants had been in the position for more than five years, occupying $54.5 \%$. The number of those who had worked for $3-5$ years was $71(35.5 \%)$. There were 20 participants with 20 years of working experience $(10.0 \%)$. This indicates that people with more than five years of working experience have been currently holding key management and leadership positions in SMEs in the tourism sector.

3.1.2 Measurement. Based on the literature review, this study generated a research measurement consisting of seven components in the research model. Leaders' professional knowledge is measured by five variables and was developed from the researches of Chawla et al. (1997) and Cong and Hai (2015). Leaders' operations management competence is measured by 10 variables and was developed from the researches of Goldberg et al. (2003), Robinson (2005) and Cong and Hai (2015). Leaders' strategic vision were measured by six variables and was developed from the study of Cong and Hai (2015). Leaders' relationships building competency is measured by six variables and was developed from the research of Chawla et al. (1997) and Cong and Hai (2015). Leaders' hands-on experience is measured by six variables and was developed from the studies of Goldberg et al. (2003), Robinson (2005). In particular, the competitiveness and performance of the enterprise in this study were approached from two aspects: customers and competitors and was developed from the works of Robinson (2005) and Cong and Hai (2015). This is because the competitiveness is not only measured by comparing to competitors within the industry (Man et al., 2002; Chawla et al., 1997) but also has to be assessed from the customer perspective (Cong and Hai, 2015). The fact that in the service industry the customers directly involve in the service creation and also be the beneficiary of these services (Cong and Hai, 2015). Details of the scale are in Appendix.

\section{Competitiveness of SMEs in tourism}

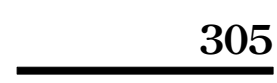


JED

23,3

306

In prior, the research employed qualitative research to understand and select the variables. A group of experts was interviewed independently with an open/closed questionnaire. Each person was asked for their opinions on particular components of leadership competencies (Cong and Hai, 2015; Chu and Hwang, 2008). A group of 10 experts (researchers, lecturers; tourism enterprise leaders and government agency managers) was selected, and they were asked to present their level of agreement regarding specific variables presented by the values on the scale from 1 to 5: (1) very irrelevant indicators; (2) not highly relevant; (3) somewhat relevant; (4) highly relevant; (5) very relevant (Cong and Hai, 2015; Chu and Hwang, 2008). Based on the evaluation, standard deviation and differences of each variable were calculated (Chu and Hwang, 2008). Research results show that all experts agreed with the observed variables proposed to measure the competitiveness of SMEs in the tourism sector in Khanh Hoa.

3.1.3 Analytical procedures. The first goal of the quantitative analysis was to confirm the related measures of intended constructs (convergent validity) and whether these constructs differed from each other (discriminant validity). The second goal was to examine appropriate constructs in the proposed conceptual model and causal relationships, as shown in Figure 1. These analyses were performed using maximum likelihood estimation in AMOS 25.0. According to Hair et al. (1998), structural equation modeling can apply a correlation matrix or a covariance matrix as a key to building any model.

Additionally, it is appropriate to use covariance to test a theory. Some indicators such as chi-squared $\left(\chi^{2}\right)$, normed fit index (NFI), relative Fft Index (RFI), Tucker-Lewis index (TLI), comparative fit index (CFI) and root mean square error of approximation (RMSEA) were applied to assess the suitability of the overall model (measurement and construct model). The appropriateness of the accepted model is denoted by NFI and CFI values, which were over 0.90 ; and RMSEA was below 0.08 . These values represent moderate relevance, while values which are less than 0.05 are relatively good (Browne and Cudeck, 1992).

\section{Research findings and discussion}

\subsection{Reliability test}

The Cronbach's alpha analysis results indicate the scores of key factors as follows: professional knowledge $=0.832$; operations management competencies $=0.939$; strategic

Figure 1.

Research model

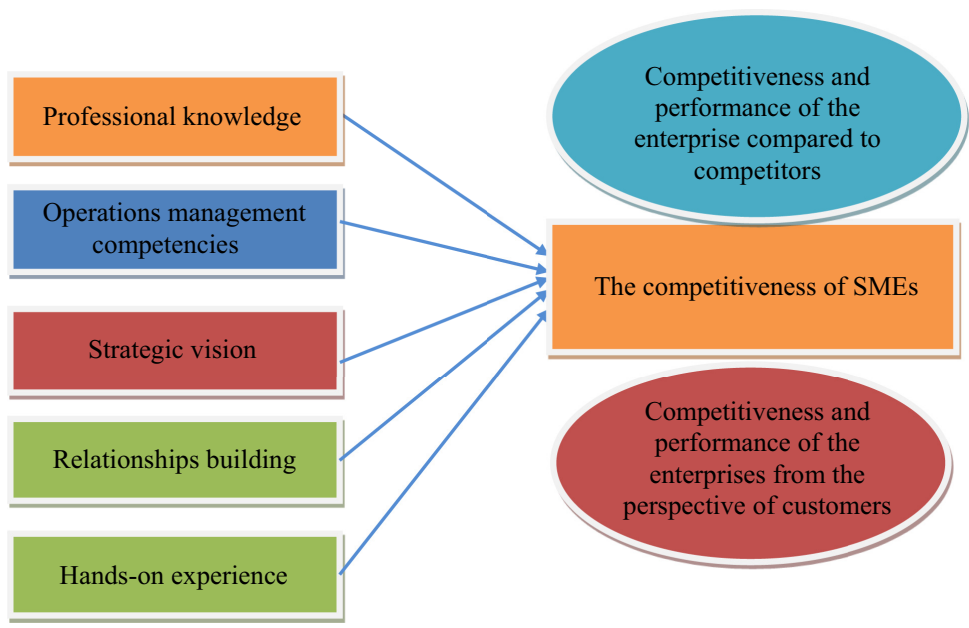


vision $=0.881$; Relationships building $=0.904$; hands-on experience $=0.836$. The analysis also indicates the score of the dependent scales including competitiveness and performance of the enterprise from the perspective of customers $=0.947$; competitiveness and performance of the enterprises compared to competitors $=0.920$. All of these are greater than 0.6. The results show that the observed variables have the appropriate correlation coefficients, which are greater than or equal to 0.3 ( $\geq 0.3$ ) (Nunnally and Bernstein, 1994) (see Table 1).

\subsection{Confirmatory factor analysis}

Table 2 displays the intercorrelations between the constructs in the theoretical model. All correlations are significant $(p<0.001 ; p<0.05$ ). A confirmatory factor analysis (CFA) of the measurement model, including five constructs in the theoretical model as in Figure 1, results in a good fit with the data $\chi^{2}=991.73$; $\mathrm{df}=573 . p=0.000$; RMSEA $=0.060$; $\mathrm{NFI}=0.912$; $\mathrm{CFI}=0.917$ ) (Browne and Cudeck, 1992). Tables 3 and 4 present the results of the CFA.

As shown in Table 3, all factor loadings on the constructs are highly significant $(p<0.001$ : $t$-value $>9.040$ ) with values ranging from 0.61 to 0.93 . which shows the convergent validity of

\begin{tabular}{|c|c|c|c|c|c|}
\hline Items & $\begin{array}{l}\text { Scale mean if item } \\
\text { deleted }\end{array}$ & $\begin{array}{l}\text { Scale variance of item } \\
\text { deleted }\end{array}$ & $\begin{array}{l}\text { Corrected item-total } \\
\text { correlation }\end{array}$ & $\begin{array}{l}\text { Alpha if item } \\
\text { deleted }\end{array}$ & \\
\hline \multicolumn{6}{|c|}{ Professional knowledge: Cronbach's alpha $=0.832$} \\
\hline \multicolumn{6}{|c|}{ Operations management competencies: Cronbach's alpha $=0.939$} \\
\hline \multicolumn{6}{|c|}{ Strategic vision: Cronbach's alpha $=0.881$} \\
\hline \multicolumn{6}{|c|}{ Relationship buildings: Cronbach's alpha $=0.904$} \\
\hline \multicolumn{6}{|c|}{ Hands-on experience: Cronbach's Alpha $=0.836$} \\
\hline \multicolumn{6}{|c|}{ Competitiveness and performance of the enterprise from the perspective of customers: Cronbach's alpha $=0.947$} \\
\hline \multicolumn{6}{|c|}{ 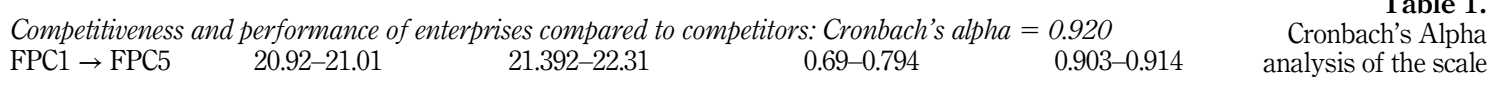 } \\
\hline
\end{tabular}

\begin{tabular}{|c|c|c|c|c|c|c|c|c|}
\hline & $\mathrm{KL}$ & $\mathrm{CL}$ & $\mathrm{VL}$ & RL & EL & FPV & FPC & \\
\hline $\mathrm{KL}$ & 1 & & & & & & & \\
\hline $\mathrm{CL}$ & $0.247^{* *}$ & 1 & & & & & & \\
\hline $\mathrm{VL}$ & $0.359^{* * *}$ & $0.404^{* * * *}$ & 1 & & & & & \\
\hline RL & $0.238^{* *}$ & $0.431^{\text {***** }}$ & $0.366^{* * * *}$ & 1 & & & & \\
\hline $\mathrm{EL}$ & $0.232^{* *}$ & $0.249^{* * *}$ & $0.404^{* * * *}$ & $0.406^{* * * *}$ & 1 & & & \\
\hline FPV & $0.353^{* * *}$ & $0.328^{* * * *}$ & $0.488^{* * * *}$ & $0.398^{* * * *}$ & $0.247^{* *}$ & 1 & & \\
\hline FPC & $0.341^{* * *}$ & $0.398^{* * * *}$ & $0.375^{* * * *}$ & $0.354^{* * * *}$ & $0.580^{\text {***** }}$ & $0.293^{* *}$ & 1 & Table? \\
\hline Mean & 5.52 & 5.51 & 5.67 & 5.35 & 5.84 & 5.66 & 5.38 & Construct means, \\
\hline SD & 1.05 & 1.16 & 1.11 & 1.26 & 1.22 & 1.11 & 1.21 & standard deviation and \\
\hline \multicolumn{8}{|c|}{$\operatorname{Note}(\mathbf{s}):{ }^{* * *} p<0.05 ;{ }^{* * * *} p<0.001$} & correlations \\
\hline
\end{tabular}




\begin{tabular}{|c|c|c|c|c|c|c|}
\hline Constructs and indicators & $\begin{array}{l}\text { Factor } \\
\text { loadings }\end{array}$ & $\begin{array}{l}\text { Standard } \\
\text { error }\end{array}$ & $\begin{array}{l}\text { Standardised } \\
\text { factor loading }\end{array}$ & $t$-value & $\mathrm{CR}$ & VE \\
\hline Professional knowledge (KL) & & & & & 0.91 & 0.67 \\
\hline KL1 & 1.000 & - & 0.825 & - & & \\
\hline KL2 & 1.038 & 0.075 & 0.829 & $13.798^{* * * *}$ & & \\
\hline KL3 & 1.085 & 0.082 & 0.806 & $13.242^{* * * *}$ & & \\
\hline KL4 & 1.067 & 0.078 & 0.827 & $13.744^{* * * *}$ & & \\
\hline KL5 & 1.294 & 0.096 & 0.819 & $13.543^{* * * *}$ & & \\
\hline
\end{tabular}
competencies (CL)
CL1
CL2
CL3
CL4
CL5
CL6
CL7
CL8

Strategic vision (VL)

VL1

VL2

VL3

VL4

Relationships buildings (RL)

RL1

RL2

RL3

RL4

RL5

RL6

Hands-on experience (EL)

EL1

EL2

EL3

Competitiveness and performance of enterprises compared to competitors (FPV)

FPV1

FPV2

FPV3

FPV4

FPV5

Competitiveness and performance of the enterprise from the perspective of customers (FPC)

FPC1

Table 3.

FPC2

FPC3

FPC4

FPC5

$\begin{array}{lc}1.000 & - \\ 1.025 & 0.082 \\ 0.833 & 0.069 \\ 0.858 & 0.078 \\ 0.914 & 0.079 \\ 1.023 & 0.082 \\ 0.859 & 0.080 \\ 0.934 & 0.103\end{array}$

0.807

0.790

0.766

0.716

0.747

0.788

0.704

0.611

1.000

1.140

0.972

1.100

0.088

0.084

0.095

\subsection{0}

1.235

1.079

1.143

1.232

1.175

0.076

0.080

0.095

0.090

0.086

1.000

1.050

1.093

0.069

0.071

$\begin{array}{lc}1.000 & - \\ 0.916 & 0.075 \\ 0.990 & 0.072 \\ 0.865 & 0.073 \\ 0.866 & 0.069\end{array}$

0.737

0.705

0.759

0.795

0.821

0.803

0.849

0.771

0.774

0.804

0.933

0.804

0.825

0.756

0.823

0.859

0.870

0.877

$\overline{-}^{\text {**** }}$
$12.005^{\text {**** }}$
$10.996^{\text {**** }}$
$11.611^{* * *}$
$12.471^{\text {**** }}$
$10.756^{* * *}$
$9.040^{\text {**** }}$

$0.88 \quad 0.64$

12.918

$11.559^{*}$

$11.615^{* * * *}$

$0.90 \quad 0.72$

$$
\begin{aligned}
& \overline{-}^{\text {**** }} \\
& 13.513^{* * *} \\
& 11.994^{* * *} \\
& 13.688^{* * *} \\
& 13.676^{* * *}
\end{aligned}
$$

$0.90 \quad 0.75$

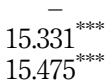

$0.88 \quad 0.58$

$-{ }^{-* * * *}$
$12.261^{* * * * *}$
$11.936^{* * * *}$
$12.469^{* * * *}$

$0.90 \quad 0.64$

$\begin{array}{lccc}1.000 & - & 0.802 & - \\ 0.943 & 0.098 & 0.784 & 9.618^{\text {**** }} \\ 1.175 & 0.113 & 0.855 & 10.376^{* * * *} \\ 1.141 & 0.105 & 0.768 & 10.874^{* * * *} \\ 1.227 & 0.109 & 0.794 & 11.212^{* * *}\end{array}$

confirmatory factor analysis coefficients and construct reliability
Note(s): All factor loadings are significant at $p<0.001$

CR: Composite reliabilities; VE: variance extracted estimate 


\begin{tabular}{|c|c|c|c|}
\hline & Criteria & Indicators & Competitiveness \\
\hline $\begin{array}{l}\chi^{2} \text { - test } \\
\chi^{2} \\
\chi^{2} / \mathrm{df}\end{array}$ & $\begin{array}{l}p<0.05 \\
<5\end{array}$ & $\begin{array}{l}992.126 \\
\quad 1.728(992.126 / 574)\end{array}$ & tourism \\
\hline $\begin{array}{l}\text { Fit indices } \\
\text { GFI } \\
\text { IFI } \\
\text { NFI } \\
\text { TLI }\end{array}$ & $\begin{array}{l}>0.90 \\
>0.90 \\
>0.90 \\
>0.90\end{array}$ & $\begin{array}{l}0.91 \\
0.91 \\
0.91 \\
0.91\end{array}$ & 309 \\
\hline $\begin{array}{l}\text { Alternative indices } \\
\text { CFI } \\
\text { RMSEA }\end{array}$ & $\begin{array}{l}>0.90 \\
<0.08\end{array}$ & $\begin{array}{l}0.91 \\
0.06\end{array}$ & $\begin{array}{l}\text { Table } 4 . \\
\text { The goodness of fit } \\
\text { indices of the model }\end{array}$ \\
\hline
\end{tabular}

the constructs. The composite reliabilities exceed the minimum value of 0.60 , and the variances extracted surpass the recommended threshold of 0.50 .

\subsection{Structural model}

The estimated results of the structural model, including only direct effects in Figure 1, indicate a good fit with the data: chi-square value $=995.126$; $\mathrm{df}=574$; $\mathrm{GFI}=0.912$; $\mathrm{CFI}=0.917 ; \mathrm{TLI}=0.914 ; \mathrm{RMSEA}=0.06$ (Browne and Cudeck, 1992). As shown in Table 5 all hypotheses involving direct effects are supported by the data.

This study expected that the professional knowledge of leaders has a direct impact on the competitiveness of SMEs, including the competitiveness and performance of the enterprises from the perspective of customers (H1) and the competitiveness and performance of the enterprise compared to competitors (H2). Both hypotheses are confirmed by the data, which indicates that professional knowledge of leaders has a significantly positive effect on the competitiveness and performance of the enterprises from the perspective of customers $\left(\beta_{1}=0.318 . t=4.155 . p<0.001\right)$ and the competitiveness and performance of the enterprise compared to competitors $\left(\beta_{2}=0.318 . t=3.290 . p<0.001\right)$.

Hypothesis 3 was that the operations management competencies of leaders have a direct impact on the competitiveness of SMEs, including the competitiveness and performance of the enterprises from the perspective of customers (H3) and the competitiveness and

\begin{tabular}{|c|c|c|c|c|c|}
\hline Scales of leadership competencies & \multicolumn{2}{|c|}{$\begin{array}{l}\text { Competitiveness and } \\
\text { performance of } \\
\text { enterprises compared } \\
\text { to competitors (FPV) }\end{array}$} & \multicolumn{2}{|c|}{$\begin{array}{l}\text { Competitiveness and } \\
\text { performance of the } \\
\text { enterprise from the } \\
\text { perspective of } \\
\text { customers (FPC) }\end{array}$} & Conclusion \\
\hline Professional knowledge (KL) & 0.318 & $4.155^{* * * *}$ & 0.318 & $3.290^{* * * *}$ & Supported \\
\hline $\begin{array}{l}\text { Operations management competencies } \\
\text { (CL) }\end{array}$ & 0.173 & $2.090^{* * * *}$ & 0.159 & $1.971^{*}$ & Supported \\
\hline Strategic vision (VL) & 0.212 & $3.398^{* * * * *}$ & 0.276 & $3.446^{* * * * *}$ & Supported \\
\hline Relationships buildings (RL) & 0.226 & $3.592^{* * * * *}$ & 0.181 & $2.295^{* * *}$ & Supported \\
\hline Hands-on experience (EL) & 0.260 & $4.207^{* * * *}$ & 0.186 & $2.359^{* * *}$ & Supported \\
\hline
\end{tabular}

Note(s): ${ }^{*} p<0.10 ;{ }^{* *} p<0.05 ;{ }^{* * *} p<0.001 ; n s$ : non-significant

Table 5.

Summary of hypothesis testing 
JED

23,3

310

performance of the enterprise compared to competitors (H4). Two hypotheses are supported by the significantly positive effect of the operations management competencies of leaders on the competitiveness of SMEs $\left(\beta_{3}=0.173 . t=2.090 . p<0.005\right) ;\left(\beta_{4}=0.159 . t=1.971 . p<0.10\right)$.

Hypotheses 5 and 6 suggested that the strategic vision of leaders would increase the competitiveness of SMEs, including the competitiveness and performance of the enterprises from the perspective of customers (H5), and the competitiveness and performance of the enterprise compared to competitors (H6). Both hypotheses are supported, indicating that the strategic vision of leaders has a significantly positive impact on the competitiveness of SMEs $\left(\beta_{5}=0.212 . t=3.398 . p<0.001\right) ;\left(\beta_{6}=0.276 . t=3.446 . p<0.001\right)$.

Hypotheses 7 and 8 proposed that the relationship building of leaders has a positive effect on the competitiveness and performance of the enterprises from the perspective of customers (H7), and the competitiveness and performance of the enterprise compared to competitors (H8). These two hypotheses are supported, showing that the relationship building of leaders are significantly positively related to the competitiveness of SMEs $\left(\beta_{7}=0.226 . t=3.592\right.$. $p<0.001) ;\left(\beta_{8}=0.181 . t=2.295 . p<0.005\right)$.

Finally, the results indicate that the hands-on experience of leaders has a strong significant positive effect on the competitiveness and performance of the enterprises from the perspective of customers $\left(\beta_{9}=0.260 . t=4.207 . p<0.001\right)$, supporting H9. The hands-on experience of leaders has a strong significant positive effect on the competitiveness and performance of the enterprise compared to competitors $\left(\beta_{10}=0.186 . t=2.359\right.$. $\left.p<0.05\right)$, supporting H10.

\section{Recommendations on policy to improve leadership competencies to enhance the competitiveness of small and medium enterprises}

This study drew on competitiveness theory to analyse the influence of leadership competencies on the competitiveness of SMEs in the tourism sector. A survey of several enterprises indicates that there are two models for evaluating the influence of leadership competencies on the competitiveness of SMEs. Firstly, the competitiveness and performance of the enterprises from the perspective of customers are affected by (1) hands-on experiences; (2) strategic vision; (3) relationship building, (4) professional knowledge and (5) operations management competencies. Secondly, the competitiveness and performance of enterprises compared to competitors are affected by (1) hands-on experience; (2) relationship building; (3) strategic vision and; (4) Operations management competencies. Based on the findings, many recommendations on the policy are proposed to improve the competitiveness of SMEs in the tourism sector in Khanh Hoa province.

First, increasing the opportunities for SMEs managers in the tourism sector in Khanh Hoa province to gain more hands-on experience. Regarding knowledge related to hands-on experience, tourism SME managers should participate in training programs, seminars and workshops organised by the Provincial SMEs Association, other consultancies and training organisations. Besides, tourism SME managers should acquire knowledge of international integration, including understanding its concept, nature, forms and characteristics; the inevitability and consequences since international integration is a major phenomenon of the modern world. Tourism SME leaders can actively find out more from books about change management, international economic integration and learn the methods to manage successfully the change from successful leaders in the country and around the world.

Secondly, increasing opportunities for tourism SME managers in Khanh Hoa province to improve their strategic vision. Tourism SME leaders can systematically register and participate in training courses, seminars and workshops for business leaders to equip strategy and vision-related knowledge such as strategic thinking, creative thinking, strategic management; strategic business development. Tourism SME leaders can choose training courses in these areas from prestigious organisations or institutions, for example, the course 
"Strategic Management in Enterprises" organised by the Center for Business Administration Study (CBAS) of the University of Economics and Business (UEB) and Vietnam National University, Hanoi (VNU). Through these courses, SME managers can understand the importance of shaping a vision for their business, how strategic management can determine the success or failure in the marketplace; know how to seize opportunities and create competitive advantages; gain and apply knowledge to build optimal strategies, to implement these strategies to each unit to ensure the efficiency, to evaluate the results and effectiveness and to adjust these strategies to adapt to the changing conditions in the business. Moreover, SME leaders can enhance their knowledge of vision and strategy development by visiting and surveying successful businesses in Vietnam or other countries to learn from their experiences. Furthermore, managers can participate in discussions amongst managers, directors who are members of the associations, clubs to gather information, share experiences and improve knowledge.

Thirdly, increase opportunities for tourism SME managers in Khanh Hoa province to expand business relationships. Research on tourism SMEs in Khanh Hoa province shows that the capability to build relationships is a component belonging to the leaders themselves, and it has a direct and positive effect on the competitiveness of SMEs. Interpretation of the differences in the research results shows that the influence of factors will vary greatly depending on the object and context of the study. From the perspective of the long-term orientation of tourism SMEs, to maintain position and sustainable competitiveness, managers are required to shape and develop a long-term strategic vision. It is vital to have a coherent strategy, which focuses on improving the quality of services, building the brand in customers' perceptions, enhancing the capability to establish relationships with partners to enhance the value of supply chain in tourism services.

Fourthly, increasing opportunities for tourism SME managers in Khanh Hoa province to improve operations management competencies. In terms of knowledge, tourism SME managers need to raise their awareness of their roles to improve operations management competencies. Leaders of tourism SMEs should attend training courses, seminars, exchange programs, as well as join associations to enhance understanding and improve knowledge. Specifically, the content includes building structure of each unit in the enterprise; the management competencies, leading people, decision-making, monitoring and evaluation. It also contains principles of training and development programs for employees in terms of human resource management like the training program "Managing people" of PACE Institute of Management. Leaders of SMEs can also learn more experiences, models of management development from organisations around the world to have a comprehensive view and skills; capability to evaluate, analysis, solve problems and plan strategy.

Fifthly, increase the opportunities for tourism SME managers in Khanh Hoa province to improve management competencies in terms of professional knowledge. To be able to understand professional knowledge in the tourism sector, managers are required to participate in tourism management programs and courses at junior colleges, colleges, universities in the mode of part-time courses or short-term training courses. Besides, managers should attend courses related to business management, financial management, market management, production management, personnel management organised by provincial business associations, training centres, government departments/divisions. For example, the training course "SMEs management skills" of AFC Institute for Financial Management equips participants with the market knowledge; business planning and production; organising of SMEs sales, human resources and financial systems; build and manage a staff of SMEs. Through this course, tourism SME managers can improve their knowledge of the domestic and foreign tourism markets, competitors, globalisation and integration; have opportunities to talk with colleagues and lecturers who have extensive 
JED

23,3

312

experience in business administration and finance; expand opportunities to interact with other enterprises and learn from successful examples.

Finally, the above results allow researchers and SMEs in tourism sectors to have a more comprehensive view of leadership factors affecting the competitiveness of SMEs in the tourism sector in Khanh Hoa province. In particular, the results show that it is necessary to focus more attention on the vital role of the leaders. At present, many enterprises hold the belief that the limitations on finances, human resources and outdated technology and facilities are considered as the major causes affecting the competitiveness SMEs in the tourism sector. In contrast, the above results show that a leader, who play a key role in every strategic decision, is the most crucial factor. Therefore, if the leaders of SMEs in the tourism sector aim to enhance their competitiveness, it can be a tremendous issue for them to believe in the fallacy of other causes rather than their leadership competencies.

This study is based on the competitiveness theory to develop the model showing the influence of leadership competencies on the competitiveness of enterprises. However, to achieve a comprehensive view, further studies need to expand other aspects based on different theories such as resources-based theories or approach competitiveness theory in terms of business fields and competitive contexts. This study collected data from managers of the small and medium hotel in Nha Trang, who age from 36 to 55. Therefore, sample representativeness is affected. Future researches are suggested to widen the sample size to fully understand the factors affecting the competitiveness of small and medium enterprises.

\section{References}

Abosede, A.J., Obasan, K.A. and Alese, O.J. (2016), "Strategic management and small and medium enterprises (SMEs) development: a review of literature", International Review of Management and Business Research, Vol. 5 No. 1, pp. 315-335.

Ai, T.H. (2013), "Factors affecting competitiveness in Vietnam's seafood exporters - the case of seafood exporters in Ba Ria - Vung Tau", Journal of Economic and Development, No. 269, pp. 51-59.

An, T.B. and Thi, D.B.V. (2012), "Research on factors affecting competitiveness of four-star hotels in Thua Thien Hue", Journal of Economic and Development, No. 261, pp. 21-29.

Anand, T. and Punia, Y. (2013), "Leadership competencies and their influence on leadership performance: a literature review", International Journal of Advanced Research in Management and Social Sciences, Vol. 2, pp. 25-31.

Asree, S., Zain, M. and Razalli, M.R. (2010), "Influence of leadership competencies and organizational culture on responsiveness and performance of firms", International Journal of Contemporary Hospitality Management, Vol. 22 No. 4, pp. 500-516.

Bharadwaj, S.G., Varadarajan, P.R. and Fahy, J. (1993), "Sustainable competitive advantage in service industries: a conceptual model and research proposition”, Journal of Marketing, Vol. 57 No. 4, pp. 83-100.

Browne, M.W. and Cudeck, R. (1992), "Alternative ways of assessing model fit", Sociological Methods and Research, Vol. 21, pp. 230-258.

Buculescu, M. (2013), "Harmonization process in defining small and medium-sized enterprises. Arguments for a quantitative definition versus a qualitative one", Theoretical and Applied Economics, Vol. 20 No. 9, pp. 103-114.

Cannon, J.P., Doney, P.M., Mullen, M.R. and Petersen, K.J. (2010), "Building long-term orientation in buyer-supplier relationships: the moderating role of culture", Journal of Operations Management, Vol. 28 No. 6, pp. 506-521.

Chawla, S.K., Pullig, C. and Alexander, F.D. (1997), "Critical success factors from an organizational life cycle perspective: perceptions of small business owners from different business environments", Journal of Business Entrepreneurship, Vol. 9 No. 1, pp. 47-58. 
Chu, H.C. and Hwang, G.J. (2008), "A Delphi - based approach to developing expert systems with the cooperation of multiple experts”, Expert Systems with Applications, Vol. 34, pp. 2826-2840.

Church, A.H. (1995), "Linking leadership behaviours to service performance: do managers make a difference?", Managing Service Quality, Vol. 5 No. 6, pp. 26-31.

Clarke, N. (2010), "Emotional intelligence and its relationship to transformational leadership and key project manager competences", Project Management Journal, Vol. 41 No. 2, pp. 5-20.

Cong, L.C. and Hai, V.H. (2015), "The influence of leaders on the competitiveness of the enterprises the case of accommodation business in Nha Trang", Journal of Trade Science, No. 14, pp. 82-93.

European Commission (2003), "What is an SME? - internal market, industry, entrepreneurship and SMEs - European commission", available at: https:/ec.europa.eu/growth/smes/businessfriendly-environment/sme-definition_en (accessed 23 March 2020).

Fraj, E., Matute, J. and Melero, I. (2015), "Environmental strategies and organizational competitiveness in the hotel industry: the role of learning and innovation as determinants of environmental success", Tourism Management, Vol. 46, pp. 30-42.

Gibson, T. and van der Vaart, H.J. (2008), "Defining SMEs: a less imperfect way of defining small and medium enterprises in developing countries", Brookings, pp. 1-29.

Goldberg, A., Cohen, G. and Fiegenbaum, A. (2003), "Reputation building: small business strategies for successful venture development”, Journal of Small Business Management, Vol. 41 No. 2, pp. 168-186.

Hair, J.F., Anderson, R.E., Tatham, R.L. and Black, W.C. (1998), Multivariate Data Analysis, 5th ed., Prentice Hall, Upper Saddle River, NJ.

Hanifah, H., Abdul Halim, H., Ahmad, N. and Vafaei-Zadeh, A. (2019), "Emanating the key factors of innovation performance: leveraging on the innovation culture among SMEs in Malaysia", Journal of Asia Business Studies, Vol. 13 No. 4, pp. 559-587.

Hieu, N.T., Trung, N.N. and Nga, N.T. (2020), "The influence of business strategy orientation on supply chain linkages and business results", Journal of Economics \& Development, Vol. 279, pp. 20-28.

Hossain, M. and Kauranen, I. (2016), "Open innovation in SMEs: a systematic literature review", Journal of Strategy and Management, Vol. 9 No. 1, pp. 58-73.

Kamp, B. and Parry, G. (2017), "Servitization and advanced business services as levers for competitiveness", Industrial Marketing Management, No. 60, pp. 11-16.

Kundu, S., Mor, A., Bansal, J. and Kumar, S. (2019), "Diversity-focused HR practices and perceived firm performance: mediating role of procedural justice", Journal of Asia Business Studies, Vol. 13 No. 2, pp. 214-239.

Lenka, U. and Agarwal, S. (2017), "Role of women entrepreneurs and NGOs in promoting entrepreneurship: case studies from Uttarakhand, India”, Journal of Asia Business Studies, Vol. 11 No. 4, pp. 451-465.

Man, T.W.Y., Lau, T. and Chan, K.F. (2002), "The competitiveness of small and medium enterprises A conceptualization with focus on entrepreneurial competencies", Journal of Business Venturing, Vol. 17 No. 2002, pp. 123-142.

Martínez-Córcoles, M., Stephanou, K.D. and Schöbel, M. (2020), 'Exploring the effects of leaders' individualized consideration in extreme contexts", Journal of Risk Research, Vol. 23 No. 2, pp. 167-180.

McAdam, R., Reid, R. and Gibson, D. (2004), "Innovation and organisational size in Irish SMEs: an empirical study", International Journal of Innovation Management, Vol. 8 No. 2, pp. 147-165.

Mohamed, M., Asmaa, M., Ichrak, T. and Youssef, R. (2013), "The issue of the definition of Moroccan SMEs and different approaches", Journal of US-China Public Administration, Vol. 10 No. 5, pp. 488-496.

Nunnally, J.C. and Bernstein, I.H. (1994), Psychometric Theory, 3rd ed., McGraw-Hill, New York, NY.
Competitiveness of SMEs in tourism 
JED

23,3

314

Organisation for Economic Co-operation and Development (OECD) (1993), Small and Medium-Sized Enterprises: Technology and Competitiveness, Taylor \& Francis, Paris.

Porter, M.E. (1985), Competitive Advantages, Creating and Sustaining Superior Performance, Macwell Macmilan, New York.

Porter, M.E. (2008), On Competition, Updated and Expanded ed., Harvard Business School Publishing, Boston.

Robinson, J. (2005), Leader of the Brand - Keeping the Best CEOs in Step; in a Highly Competitive and Unpredictable Global Market, a Strong Brand Delivers a Compelling Market Advantage, New Zealand Management, p. 26.

Tho, N.D. and Trang, N.T.M. (2009), "Business orientation, creative capacity, marketing capacity and business results of the enterprise", Journal of Economic \& Development, Vol. 108, pp. 56-62.

United States International Trade Commission (2010), "Small and mediumsized enterprises: overview of participation in U.S. exports", Usitc.gov, available at: https://www.usitc.gov/publications/332/ pub4125.pdf (accessed 23 March 2020).

Voola, R., Casimir, G., Carlson, J. and Agnihotri, M.A. (2012), "The effects of market orientation, technological opportunism, and e-business adoption on performance: a moderated mediation analysis", Australasian Marketing Journal, Vol. 20, pp. 136-146.

Zainudin, R., Mahdzan, A.N. and Leong, E. (2018), "Firm-specific internal determinants of profitability performance: an exploratory study of selected life insurance firms in Asia”, Journal of Asia Business Studies, Vol. 12 No. 4, pp. 533-550.

\section{Further reading}

Davis, P.S., Dibrell, C.C. and Janz, B.D. (2002), "The impact of time on the strategy-performance relationship implications for managers", Industrial Marketing Management, Vol. 31 No. 4, pp. 339-347.

Globerson, S. and Zwikael, O. (2002), "The impact of the project manager on project management planning processes", Project Management Journal, Vol. 33 No. 3, pp. 58-64.

Nair, J., Chellasamy, A. and Singh, B. (2019), "Readiness factors for information technology adoption in SMEs: testing an exploratory model in an Indian context", Journal of Asia Business Studies, Vol. 13 No. 4, pp. 694-718.

Pullman, M.E., Verma, R. and Goodale, J.C. (2001), "Service design and operations strategy formulation in multicultural markets", Journal of Operations Management, Vol. 19 No. 2, pp. 239-254.

Tho, N.D. (2017), "Firm capabilities and performance: a necessary condition analysis", Journal of Management Development, Vol. 37 No. 4, pp. 322-332.

\section{Appendix}

\begin{tabular}{ll} 
Items & Leadership competencies criteria \\
\hline KL & Professional knowledge Chawla et al. (1997) and Cong and Hai (2015) \\
KL1 & Business development in tourism \\
KL2 & Market and competitors \\
KL3 & Tourism marketing \\
KL4 & Globalisation and integration in the tourism business \\
KL5 & Society, communities, and the environment \\
CL & Operations management competencies Goldberg et al. (2003), Robinson (2005); and Cong and Hai \\
& (2015) \\
CL1 & Establishing the organisational structure \\
CL2 & Managing all the units in the company
\end{tabular}


Items Leadership competencies criteria

CL3 Executing the activities of all units in the company

CL4 Leading the company

CL5 Directing the company

CL6 Making a strategic decision

CL7 Monitoring activities in the company

CL8 Evaluating activities in the company

CL9 Adjusting the business field of the company

CL10 Changing the business field of the company

VL Strategic vision (Cong and Hai, 2015)

VL1 Recognising tourism business opportunities in Khanh Hoa province

VL2 Seizing the opportunities to lead the company to success in the tourism business

VL3 Recognising threats in the tourism business

VL4 Leading the company to overcome the threats in the tourism business

VL5 Recognising the potential resources of the company in the tourism business

VL6 Recognising opportunities than competitors in the tourism business

RL Relationships building competencies (Chawla et al., 1997; Cong and Hai, 2015; Tho and Trang, 2009)

RL1 Establishing internal relationships

RL2 Establishing relationships with superiors

RL3 Building relationships with strategic partners

RL4 Building relationships with customers

RL5 Building relationships with suppliers

RL6 Building relationships with administrative agencies

EL Hands-on experience (Goldberg et al., 2003; Robinson, 2005)

EL1 I have held many different managing positions in the company

EL2 I had experience aiding the company to overcome difficulties

EL3 I held a position in the company in a specified period

FPC Competitiveness and performance of enterprises compared to competitors (Robinson, 2005; Cong and Hai, 2015)

FPC1 Our company achieve more success than our competitors

FPC2 In general, our revenue is higher the direct competitor's one

FPC3 Our larger market share is larger than the direct competitor's one

FPC4 Our profit is higher than the direct competitor's one

FPC5 Our profit margin is higher than the direct competitor's one

FPC6 Our rate of return on investment is higher than the direct competitor's

FPC7 Our customer loyalty is higher than the direct competitor's one

FPV Competitiveness and performance of the enterprise from the perspective of customers (Cong and Hai, 2015; Tho and Trang, 2009)

FPV1 Customer loyalty is higher than last year

FPV2 Customer satisfaction is higher than last year

FPV3 Customers increasingly bond with the company's products/services

FPV4 Customers make more returns to the company

FPV5 Customers are more pleased with the company's products/services

FPV6 Customers are more interested in the company's products/services

FPV7 Customers are more satisfied with the company's products/services
Competitiveness of SMEs in tourism
Table A1. 
About the authors

Le Chi Cong is an Associate Professor of Tourism Faculty at Nha Trang Univerisity. His research interests are destination quality, satisfaction of visitors, satisfaction-loyalty consistency. His recent works have appeared in Journal of Food Quality and Preference; Journal of Hospitality and Tourism Management; Asia Pacific Journal of Marketing and Logistics; International Journal of Tourism Cities; Tourism Planning and Development; Journal of Economics and Development (Vietnam). Le Chi Cong is the corresponding author and can be contacted at: conglechi@ntu.edu.vn

Dao Anh Thu is a Lecturer in the Tourism Faculty at Nha Trang University. She teaches on the marketing in hospitality. Her areas of study are marketing communications, consumer behaviour and organisational behaviour.

For instructions on how to order reprints of this article, please visit our website: www.emeraldgrouppublishing.com/licensing/reprints.htm Or contact us for further details: permissions@emeraldinsight.com 